\title{
Erectile dysfunction: a couple problem
}

\author{
Susan Quilliam
}

\section{Background}

It used to be called 'impotence': a double-edged label, with its implication not only that the man is unable to persuade blood into his penis, but also that he's powerless in sexual situations, in the relationship arena, and in life. The word was never just a medical description; it always held undertones of accusation - a word to be hurled across the room during late-night arguments. How preferable that we now use the term 'erectile dysfunction' (ED): descriptive, non-judgmental, and with no misunderstandings.

Problem is, there's still a misunderstanding here, and a serious one at that. We still think that ED is only about the man, his penis and his problem. Wrong. Yes of course the man suffers - and deeply. It's not just the day-to-day lack of sexual performance, not just the panic that normal service will never be resumed. It's also the low self-esteem, the failing confidence when he compares himself with other men. It's the guilt at what he sees as failure towards his partner. And it's the intimation if not of mortality, certainly of frailty and old age. ED can all too easily turn into a symbol of male helplessness and hopelessness, which is why the original 'im-potent' term struck disturbingly to the very heart of the problem.

So yes, the man suffers. But what not only my postbag but recent studies ${ }^{1}$ suggest is that the man's partner suffers too. And that means that his ED can also become her (or conceivably, his) sexual and emotional dysfunction, and then become a relationship dysfunction rippling out through the whole of the couple's lives.

\section{The partner's problem}

So where the man may feel low in self-esteem, his partner may question her own attractiveness, her own sexual skill, her own ability to keep her man focused. Where the man may feel unlovable, his partner may feel unloved, interpreting his inability to perform as proof-positive of her inability to keep his interest. As an agony aunt, I get letter after letter from readers who rather than seeing their man's ED as being a symptom of diabetes or heart disease - as we health professionals would do - see it as a symptom of fading love, failing commitment, or the existence of 'another woman'.

And that, of course, may trigger anger. She may be angry that he isn't performing - either because she actively needs penetration in order to feel physical release or because she needs the unity of intercourse to feel emotionally reassured. He, meanwhile, may become caught between anger at himself that he isn't performing and anger at her that she objects to his not performing. At that point it isn't just their sex life that starts to fail; underlying fury and resentment erodes loving communication, undermines years of trust, loosens all the bonds of affection.

J Fam Plann Reprod Health Care 2007; 33(1): 61-62

\section{Cambridge, UK}

Susan Quilliam, BA, Cert Ed, MNLP, Freelance Writer, Broadcaster and Agony Aunt

Correspondence to: Ms Susan Quilliam.

E-mail: susan@susanquilliam.com
In short, through self-doubt, mistrust, catastrophic thinking or just plain ignorance, partners often make what we health professionals may see as a simple, and simply cured, hydraulics problem into a major relationship challenge. It takes extreme inner strength - and couple commitment - to weather this kind of storm.

\section{Twist in the tale}

There is, however, a twist to this particular tale - one that is explored elsewhere in this issue of the Journal but which nevertheless deserves a mention here. ED will almost always leave male partners suffering as described above. But, just sometimes, it becomes not a problem for a female partner but a welcome relief. For women, ED may mean either a shift of focus from vagina to clitoris or a total cessation of sexual activity - and either or both of these options may be what she's longed for!

We still think that erectile dysfunction is only about the man, his penis and his problem.

If so, the resolution of the ED may actually mean a slump in her relationship satisfaction - the man's dream solution to the problem may actually be the woman's worst nightmare. It's always worth checking when a male states confidently that this is going to make his wife a happy woman that he's actually checked out the truth of that statement with her!

\section{The professional's opportunity}

What all this means for us, as medical professionals, is that the ED patient rarely walks into our consulting room alone. He not only brings with him an age of physical symptoms and self-doubt (50\% of men struggle on for 2 years before seeking expert advice $)^{2}$ - he may also bring with him (both metaphorically and literally) a distressed partner and a relationship under strain. So we as physicians may need not only to tackle the physical difficulty - the ED and any triggering medical problem - we may also need to at the very least be aware of, and ideally offer some help for, the emotional backlash that his problem has created.

How to do that? Perhaps the main weapon in our armoury is the simple fact that ED is not only a common problem but often a medical one. The patient who learns that $25 \%$ of men worldwide suffer from ED at some time in their lives ${ }^{3}$ will almost inevitably feel more positive. If this patient can then be reassured that his ED is down to a specific physical condition that can be treated, then even though he may worry about the ramifications of that condition, worries about his sexuality and his masculinity will be massively alleviated. If he then reports all that back to his partner, the partner's level of self-blame, suspicion and anger will fall, and their relationship has a good chance of recovery.

Of course, such success depends on the communication skills of practitioners. This process of normalising the condition and offering hope of recovery needs to be done not only clearly and in a way patients can understand, it also needs to be done in an affirming way. Because what patients with ED and their partners need above all is to feel that on some level they're succeeding. They've lived with 
the spectre of failure, both sexual and emotional, for far too long - they need to be told they're getting something right. It's helpful - as well as accurate - to tell patients that "many couples find difficulty with ED - the fact you're still together is a real sign of the strength of your relationship".

\section{Rebuilding}

Many couples, of course, will need more than simple validation - they'll need help in rebuilding their sex life. For most, it won't be a case of taking the treatment and instantly leaping on top of each other - not after years of withholding touch for fear of raising (or rather, not raising) the erection question. So it may be useful to give patients very basic advice: to reintroduce sex slowly, to include foreplay, to relax if things don't go according to plan first time round - and to come back if treatment doesn't work, with the reassuring rider that many treatment plans need adaptation.

\section{They've lived with the spectre of failure for far too long; they need to be told they're getting something right.}

Couples may also need help in rebuilding their relationship, or at the very least they may need to hear that seeking such help is not only common but also a sign of commitment rather than weakness. I would argue that every approach to ED - be that a script for medication or a referral on for further tests - be accompanied by at least a mention that the man and his partner may want to see a counsellor. Many won't need it but many will, and a blanket suggestion will make sure that those patients too embarrassed to admit partnership issues don't slip through the net.

\section{The good news}

The good news, then, is that treatment, support and referral are highly effective tools to tackle the couple issues that spin out from ED, and it's therefore totally reasonable to expect that with this support solving a man's ED will restore not only his sexual prowess but, over time, his and his partner's self-esteem and their relationship stability.

But there also may be an unexpected bonus. While researching this article, I came across a recent study ${ }^{4}$ suggesting that when men are successfully treated for ED their partners show a rise not just in emotional positivity
Box 1: Erectile difficulty, a couple problem: suggested tenpoint action plan

- Be aware: when a patient presents with erectile difficulty, expect that there have been couple problems.

- Ask: a simple question such as "How does your partner feel about this?" is a good way in.

- Normalise: tell the patient clearly that erectile dysfunction is a common problem and often down to medical rather than relationship causes.

- Validate: however troubled their story, point out what the patient and his partner are doing right.

- Invite partner attendance: or at the very least, check with the patient that his partner knows what is happening

- Encourage negotiation: encourage communication so both partners get what they want as they resume their sex life.

- Inform: if you suspect a lack of sexual knowledge or skill is adding to a couple's problems, give information.

- Pace: suggest the couple reintroduce sex gradually and that they not panic if treatment doesn't work first time.

- Reassure: make sure patient understands that coming back for 'tweaking' of treatment is to be expected.

- Refer on: mention and normalise couple counselling as a matter of course (www.relate.org.uk).

and sexual fulfillment, but also in physiological arousal, lubrication and arousal. Tackling ED may not only bring a smile to his face. It may also leave her smiling, too.

\section{Statements on funding and competing interests}

Funding None identified.

Competing interests Susan Quilliam is a member of Bayer HealthCare's Global Advisory Board and Women's Advisory Board for Levitra ${ }^{\circledR}$.

\section{References}

1 Fisher WA, Meryn S, Sand M, Bradenburg U, Buvat J, Mendive $\mathrm{J}$, et al. Communication about erectile dysfunction among men with ED, partners of men with ED, and physicians: The Strike Up a Conversation Study (Part 1). J Mens Health Gender 2005; 2: 64-78.

2 Haro JM, Beardsworth A, Casariego J, Gavart S, Hatzichristou D, Martin-Morales A, et al. Treatment-seeking behavior of erectile dysfunction patients in Europe: results of the Erectile Dysfunction Observational Study. J Sex Med 2006; 3: 530-540.

3 'Sex and the Modern Man'. A report based on a global survey commissioned by Bayer HealthCare, 2005. http://www. vitalsexual.com [Accessed 12 October 2006].

4 Goldstein I, Fisher WA, Sand M, Rosen R, Mollen M, Brock G, et al. Women's sexual function improves when partners are administered vardenafil for erectile dysfunction: a prospective, randomized, double-blind, placebo-controlled trial. J Sex Med 2005; 2: 819-832.

\section{BOOK REVIEW}

Sexual Health for Men: Answers at Your Fingertips. P Kell, V Griffiths. London, UK: Class Publishing, 2006. ISBN: 1-85959-011-X. Price: $£ 14.99$ (currently available from the publisher's website at the special offer price of $£ 7.99)$. Pages: 181 (paperback)

My main issue with this book is that, quite simply, it doesn't do what it says on the tin. The title, Sexual Health for Men, suggests a wideranging tome that explores all aspects of male sexual well-being. Yet the book majors almost exclusively on erectile dysfunction (ED) and ignores most other sexual issues: sexually transmitted infections, for example, don't even get a mention in the index!

That's the bad news. The good news, however, is that the book's concentration on physiologically caused ED is superb. The book utterly meets its market - ED patients and their partners - exploring the problem in depth, with an excellent 'question and answer' structure that really reflects typical issues and concerns. And it does this without falling into the two common traps of self-help books, namely being too academic or too patronising. The authors' medical background and experience means they are playing to their strengths here and it shows.

No, I wouldn't recommend this book for patients whose ED has already been diagnosed as psychological or relational. The book addresses these issues, but doesn't go into depth about underlying causes or even treatments; sensate focus, for example, is disposed of in one page.

But I would unhesitatingly recommend this to a patient who has been diagnosed with physiologically caused or medically treatable ED, or a health professional who needs an overview or reminder of the problem and its current solutions. The content is exhaustive, the index comprehensive, the 'useful addresses' section sound, the glossaries of medical terms spot on.
The section on treatments was outstanding, explaining the 'pros and cons' of drug treatments in an easily accessible way, enabling any patient to weigh up the 'pros and cons' and appear in the consulting room both informed and resourced.

Above all, the book caters to every major concern that a man with ED and his partner might have, taking a range of viewpoints and a whole spectrum of issues. I particularly liked the 'question' purporting to come from the wife of a GP who himself had ED and was wary of approaching colleagues with his problem.

In short, if this book were re-titled Physiologically Induced ED: The Ultimate Guide, I'd award it a perfect '10'.

Reviewed by Susan Quilliam, BA, Cert Ed, MNLP Freelance Writer, Broadcaster and Agony Aunt, Cambridge, UK 